\title{
The collapse and continued low productivity of a keystone forage fish species
}

\author{
Alejandro D. Buren ${ }^{1, *}$, Hannah M. Murphy ${ }^{1, *, * *}$, Aaron T. Adamack ${ }^{1}$, \\ Gail K. Davoren ${ }^{2}$, Mariano Koen-Alonso ${ }^{1}$, William A. Montevecchi ${ }^{3}$, \\ Frances K. Mowbray ${ }^{1}$, Pierre Pepin ${ }^{1}$, Paul M. Regular ${ }^{1}$, Dominique Robert ${ }^{4}$, \\ George A. Rose ${ }^{5}$, Garry B. Stenson ${ }^{1}$, Divya Varkey ${ }^{1}$ \\ ${ }^{1}$ Northwest Atlantic Fisheries Centre, Fisheries and Oceans Canada, St. John's, NL A1C 5X1, Canada \\ ${ }^{2}$ Department of Biological Sciences, University of Manitoba, Winnipeg, MB R3T 2N2, Canada \\ ${ }^{3}$ Cognitive and Behavioural Ecology Programme, Departments of Biology and Psychology, \\ Memorial University of Newfoundland, St. John's, NL A2H 5G5, Canada \\ ${ }^{4}$ Institut des sciences de la mer, Université du Québec à Rimouski, Rimouski, QC G5L 3A1, Canada \\ ${ }^{5}$ Institute for the Oceans and Fisheries, University of British Columbia, Vancouver, BC V6T 1Z4, Canada
}

\begin{abstract}
Capelin are a focal forage species in the Northwest Atlantic ecosystem as they act as an energy conduit from lower to higher trophic levels. Fisheries and Oceans Canada determined that the Newfoundland capelin stock (Northwest Atlantic Fisheries Organization Divisions 2J3KL) suffered an order of magnitude decline in biomass in 1990-1991. This collapse was concomitant with drastic changes observed in the ecosystem during the late 1980s and early 1990s. While the results of more than a dozen studies have supported the capelin stock collapse hypothesis, an alternative non-collapse hypothesis proposed that rather than collapsing in 1990-1991, the capelin stock either (1) changed its migratory patterns while the timing of the spring capelin acoustic survey remained constant, leading to a spatio-temporal mismatch between the spring acoustic survey and the stock, or (2) became less migratory and remained inshore year-round, therefore being largely underestimated by the offshore spring and fall acoustic surveys. The collapse and non-collapse hypotheses were tested using multiple independent data sets, which included both fishery-dependent (inshore commercial catch) and fishery-independent (spring and fall acoustic and fall bottom-trawl surveys, capelin larval indices, aerial surveys, predator diet and behavior) data, and diverse statistical methods. The weight of evidence approach led us to reject the non-collapse hypothesis and conclude that the Newfoundland capelin stock did collapse in 1990-1991 with minimal recovery over the subsequent 3 decades.
\end{abstract}

KEY WORDS: Capelin $\cdot$ Mallotus villosus $\cdot$ Acoustic survey $\cdot$ Regime shift $\cdot$ Newfoundland

\section{INTRODUCTION}

Forage fish play crucial roles in many ecosystems, transferring the bulk of the energy from lower trophic levels to high trophic level predators. Typically, forage fish are small shoaling species that are characterized by short life expectancy and rapid, but variable, somatic growth driven by environmental factors. Forage fish species often exhibit 'boom and bust' population dynamics, i.e. their abundances

\footnotetext{
${ }^{*}$ These authors contributed equally to this work

${ }^{* *}$ Corresponding author: hannah.murphy@dfo-mpo.gc.ca
}

change rapidly and substantially and undergo phases of extremely high or extremely low abundances (Schwartzlose et al. 1999, Chavez et al. 2003). Each of these phases can last for prolonged periods. For example, the Norwegian spring-spawning Atlantic herring Clupea harengus stock collapsed in the late 1960s after a pulse of overfishing and remained at very low levels until the late 1980s (Toresen \& Østvedt 2000, Skagseth et al. 2015), while sardine Sardinops sagax and anchovy Engraulis spp. have

(c) G. Davoren, W. Montevecchi, D. Robert, G. Rose and Fisheries and Oceans Canada 2019. Open Access under Creative Commons by Attribution Licence. Use, distribution and reproduction are unrestricted. Authors and original publication must be credited. 
decade-scale regimes of high and low abundances where populations thrived for 20 to $30 \mathrm{yr}$ and then disappeared for similar periods (Schwartzlose et al. 1999, Chavez et al. 2003).

Capelin Mallotus villosus is the focal forage fish species in the North Atlantic Ocean ecosystems (Templeman 1948, Vilhjálmsson 1994, Carscadden et al. 2001). The 3 largest and most economically valuable capelin stocks in the North Atlantic are in the Barents Sea, off the coast of Iceland, and along the Newfoundland and Labrador (Canada) continental shelf. The Barents Sea capelin stock experienced 4 collapses over the past 4 decades: the mid- to late1980s, the mid-1990s, the mid-2000s, and the mid2010s. The size of the stock fluctuated between 3 and 6 million tonnes (Mt) during the 'boom' phases and around $0.2 \mathrm{Mt}$ during the 'bust' phases. There is general agreement that ecosystem changes, both bottom-up (i.e. temperature and North Atlantic Oscillation effects) and top-down forces (i.e. predation), were behind these 'boom-bust' dynamics (Gjøsæter et al. 2009, Hjermann et al. 2010). The Icelandic capelin stock underwent similar dynamics, with 3 'bust' phases over the past 4 decades: the early 1980 s, the early 1990s, and most of the 2000s. The size of the stock was approximately 1.5-2 Mt during the 'boom' phases and between 0.1-0.5 Mt during the 'bust' phases (ICES 2017). The first 2 'bust' phases were due to a combination of poor recruitment and the stock being easily available to the fishing fleet, while the most recent 'bust' phase was associated with poor recruitment attributed to an increase in the inflow of Atlantic water north of Iceland and a climate-related shift in distribution (Pálsson et al. 2012, Carscadden et al. 2013).

Fisheries and Oceans Canada (DFO) concluded that the Northwest Atlantic Fisheries Organization (NAFO) Divisions 2J3KL capelin stock (hereafter, Div. 2J3KL capelin stock) experienced an order of magnitude decline in 1990-1991 with minimal recovery during the subsequent 3 decades (DFO 1994, 2018, Miller 1994). The size of the stock fluctuated between 2-6 Mt from 1982-1990, and between 0.03-1.0 Mt during the ensuing period (DFO 2018). The decline in capelin biomass was concomitant with drastic changes in the ecosystem during the late 1980s and early 1990s (deYoung \& Rose 1993, Montevecchi \& Myers 1997, Lilly et al. 2000, Pedersen et al. 2017), including major changes in the biology and ecology of capelin, such as delayed and protracted spawning, changes in their geographical and vertical distribution, and declines in somatic condition and size and age at maturity (Frank et al. 1996, Carscadden et al. 2001, Mowbray 2002,
Nakashima \& Wheeler 2002, DFO 2018). The collapse and minimal recovery of capelin since 1990-1991 is hypothesized to have been due to bottom-up processes that affected the recruitment and survival of capelin (Buren et al. 2014a, Obradovich et al. 2014, Murphy et al. 2018).

Frank et al. (2016) presented an alternative hypothesis: the Div. 2J3KL capelin stock did not collapse in the 1990s. The non-collapse hypothesis postulates that the offshore spring and fall acoustic surveys failed to detect large capelin aggregations since 1990 because of a spatio-temporal mismatch between the acoustic surveys and the stock. Specifically, the hypothesis states that post-1990, either (1) capelin changed their migratory patterns while the timing of the spring acoustic survey remained constant, leading to a spatio-temporal mismatch between the spring acoustic survey and the stock, or (2) capelin became non-migratory in 1990 and were therefore undetected by the offshore spring and fall acoustic surveys. Support for the non-collapse hypothesis was based on changes in the biology of capelin post-1990 (e.g. distribution and demography), re-analysis of the offshore research surveys (fall bottom-trawl and acoustic), and the response of various components of the ecosystem (e.g. zooplankton, Atlantic cod Gadus morhua, seabirds, Northwest Atlantic harp seals Pagophilus groenlandicus) to the large-scale changes that occurred in the region in the early 1990s. The objective of the current paper was to assess the empirical support for the capelin collapse hypothesis versus the non-collapse hypothesis using multiple independent data sets and diverse statistical methods (e.g. triangulation, sensu Munafò \& Davey Smith 2018). The weight of evidence approach led us to reject the non-collapse hypothesis and conclude that the Div. 2J3KL capelin stock did collapse in 1990-1991 with minimal recovery over the subsequent 3 decades (see Table 1).

\section{MATERIALS AND METHODS}

\subsection{Offshore capelin abundance: acoustic surveys}

To test the hypothesis of a resident inshore capelin population, the acoustic biomass estimates from 2 inshore acoustic surveys were analyzed and integrated with estimates of offshore capelin biomass. A seasonal acoustic survey of Trinity Bay, Newfoundland and Labrador (NL) (see Fig. 1) was conducted in September and October 2003, and January, June and September 2004-2005 for on average $12 \mathrm{~d}$ (range: 4-28 d) 
per sampling month from a $23 \mathrm{~m}$ inshore research vessel (CCGS 'Shamook') using a calibrated EK500 echo-sounder with a towed $38 \mathrm{kHz}$ transducer. The acoustic survey followed a fixed transect design that covered both the main portion of Trinity Bay as well as the 4 arms (Fig. S1 in Supplement 1 at www.int-res. com/articles/suppl/m616p155_supp1.pdf). The annual offshore spring (May) acoustic survey on the CCGS 'Teleost' (equipped with either an EK500 [1999-2011] or an EK60 [2012-2017] echo-sounder) was extended inshore into Trinity Bay beginning in 1999 with no inshore surveys in 2006 and 2014-2016. The inshore component of the spring acoustic survey followed the same methods as the seasonal survey except only the main portion of the bay was surveyed in 2-4 d (Fig. S2 in Supplement 1). When acoustic targets were encountered during a $24 \mathrm{~h}$ period, sampling was conducted using either a bottom or midwater trawl to target the portion of the water column where the acoustic signal occurred. Length, sex, and maturity stage were recorded for all capelin sampled, and ages were determined for 2 fish per sex per $0.5 \mathrm{~cm}$ interval. For methods to calculate capelin biomass from acoustic backscatter data, see Mowbray (2002). To estimate the seasonal mean density of capelin in Trinity Bay, we only used the biomass estimates from the main portion of the bay. If the Div. 2J3KL capelin stock did not collapse, the inshore acoustic surveys should detect a large inshore resident capelin population composed of all age classes and spent/recovering fish inshore after summer spawning.

In years when the annual offshore spring acoustic survey included an inshore component (1999-2005, 2007-2013, 2017), the capelin biomass inshore and offshore were directly compared using a Pearson correlation. If the Div. 2J3KL capelin stock did not collapse, there should be a significant negative correlation between the inshore and offshore survey components (i.e. years with high capelin biomass inshore should have low biomass offshore).

The mean inshore capelin density $\left(\mathrm{kg} \mathrm{km}^{-2}\right)$ that is required to compensate for the missing 3-6 Mt of capelin from the offshore was calculated. Each year, approximately $71000 \mathrm{~km}^{2}$ of the NL coast remains poorly surveyed and un-surveyed in the offshore fall bottom-trawl survey (FBTS) (i.e. see Fig. 4, red and pink areas) (see Brodie 2005 for maps of survey strata). We simply calculated the mean density that would be required for a total biomass of 3-6 Mt of capelin to be present in these nearshore areas. This density was compared to the mean seasonal density estimates obtained from the inshore surveys (2003-2005).

\subsection{Offshore capelin distribution: annual multi-species bottom-trawl surveys}

To test the hypothesis of a shoreward shift in capelin distribution since 1990, the center of gravity (CG) analysis of the FBTS data (e.g. DFO 2015, Frank et al. 2016) was revisited by calculating the annual CG and inertia for the years 1983-2016 (cf. Woillez et al. 2007). The CG metric was calculated by weighting the mean latitudes and longitudes of survey sets by abundance:

$$
C G=\frac{\sum_{i=1}^{n} x_{i} s_{i} z_{i}}{\sum_{i=1}^{n} s_{i} z_{i}}
$$

where $x_{i}$ represents the coordinates of the sets, $z_{i}$ is abundance, and $s_{i}$ is the area of influence (Woillez et al. 2007). Given the irregular spatial sampling of the FBTS, the CG indicator was weighted by area of influence, which was calculated using Voronoï tessellation of sets conducted within the survey strata each year (Woillez et al. 2009). The spatial dispersion of the population around its CG (i.e. inertia, I) was also calculated:

$$
I=\frac{\sum_{i=1}^{n}\left(x_{i}-C G\right)^{2} s_{i} z_{i}}{\sum_{i=1}^{n} s_{i} z_{i}}
$$

and this spatial indicator was decomposed into 2 orthogonal axes describing the maximum and minimum components $I$. The shape of the dispersion around CG was quantified by taking the square root of the ratio of the maximum and minimum components (Woillez et al. 2007). These calculations were conducted in $\mathrm{R}$ ( $\mathrm{R}$ Core Team 2018) using the 'RGeostats' package (Renard et al. 2018).

The trawl gear used on the FBTS was changed in 1995 (Engel otter trawl from 1978-1994; Campelen 1800 shrimp trawl from 1995 onwards). Both FBTS data sets were included in the CG analysis even though there is no conversion factor for the change in catchability of capelin in the FBTS when the trawl gear changed in 1995. Since the CG was calculated by year and its mean coordinate was weighted by abundance, the CG was relative within each year regardless of the probability of catching capelin (Figs. S3-S5 in Supplement 2 at www.intres.com/articles/suppl/m616p155_supp2.html).

\subsection{Inshore recruitment index}

The capelin larval productivity analysis of Frank et al. (2016) was re-examined by comparing late-larval densities between years prior to and since 1991. 
August densities were used pre-1991 and September densities since 1991, as the persistently late spawning of capelin since 1991 has delayed capelin larval emergence. This allowed a comparison of the productivity of similar larval developmental stages (Nakashima \& Mowbray 2014).

\subsection{Weight of evidence}

Each 'Result' section, which was organized to address similar lines of evidence as Frank et al. (2016), first reviews the relevant literature, presents results from new analyses, and concludes by summarizing support for each alternative hypothesis. Once all evidence was presented, the weight of evidence approach was used to determine, overall, which alternative hypothesis was best supported by the combination of previously published results and additional analyses based on independent data sets.
1990, the Canadian fall acoustic survey reported a very low capelin biomass $(0.1 \mathrm{Mt},<5 \%$ of the biomass surveyed in 1989) while the USSR acoustic survey reported the smallest biomass since 1984 (0.6 Mt) (Winters 1995) (Fig. 2). Both the USSR and Canadian acoustic surveys reported record low capelin biomass in the fall of 1991 and 1992 (0.02-0.06 Mt) (Winters 1995). A Canadian expanded fall survey (Divs. 2J3KL) in 1993-1994 was conducted to determine if the 'missing' capelin could be located. However, the expanded fall acoustic survey confirmed the findings of the 1991-1992 fall surveys that offshore capelin biomass was at a record low (Miller 1994, 1995).

Consistent with the fall acoustic surveys, both the Canadian (Div. 3L; 1982-1992, 1996, 1999-2005, 2007-2015, 2017) and the USSR (Divs. 3LNO; 19751994) spring offshore acoustic surveys reported record low capelin biomass in 1991 (Bakanev 1992, Mowbray 2014) (Figs. 1 \& 2). The spring acoustic surveys encompassed an important capelin nursery area

\section{RESULTS}

\subsection{Capelin}

3.1.1. Offshore capelin abundance: acoustic surveys

From 1982-1992, Canada conducted fall (October) acoustic surveys for capelin in NAFO Divs. 2J3K (hereafter Divs. 2J3K) (Fig. 1) (e.g. Miller \& Carscadden 1983, Miller \& Lilly 1991). The fall acoustic surveys targeted the maturing portion of the stock during winter feeding migrations to provide estimates of the size and number of maturing fish being recruited to the fishery the following year (Mowbray 2014). The Div. 2J3KL capelin stock was also acoustically surveyed by the former Union of Soviet Socialist Republics (USSR) in Divs. 2J3K in November from 1982-1992 (Fig. 1) (Bakanev 1992). The USSR fall acoustic surveys were conducted approximately 1 mo later than the Canadian surveys and consistently estimated higher capelin abundances, which may have been due to timing, as capelin start aggregating into large overwintering shoals in November (Winters 1995). In

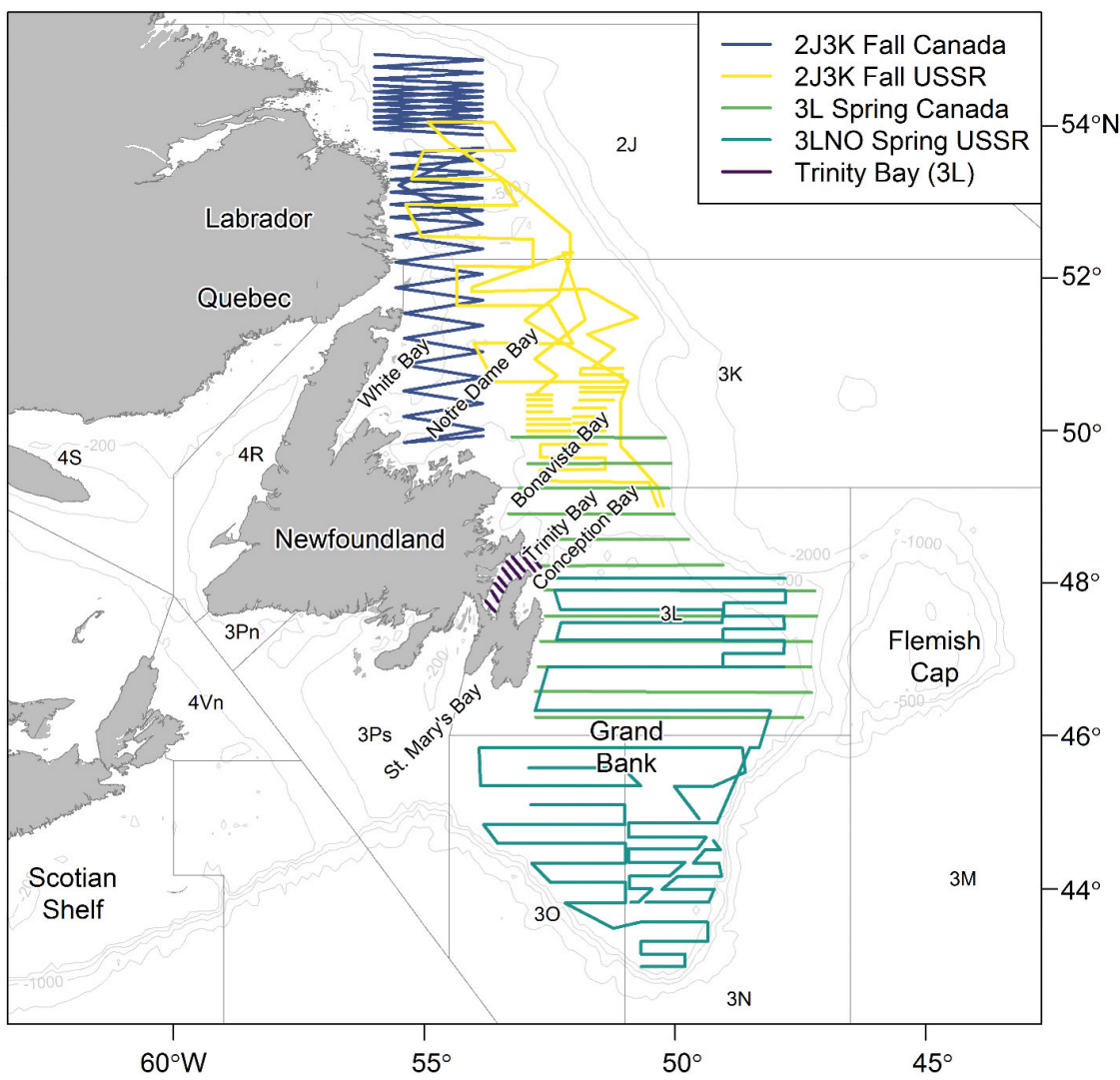

Fig. 1. Capelin stock area in Northwest Atlantic Fisheries Organization (NAFO) Divisions 2J3KL including embayments and major submarine banks surrounding Newfoundland and Labrador, Canada. Included are the acoustic survey tracks conducted in Div. 3L (offshore) and Trinity Bay (inshore) in May 2018 by Canada (DFO unpubl. data); Divs. 3LNO in June 1991 by the former USSR (see Bakanev 1992 for more details); Divs. 2J3K in October 1983 by Canada (see Miller \& Carscadden 1983 for more details); and Divs. 2J3K in November 1991 by the former USSR (see Bakanev 1992 for more details) 


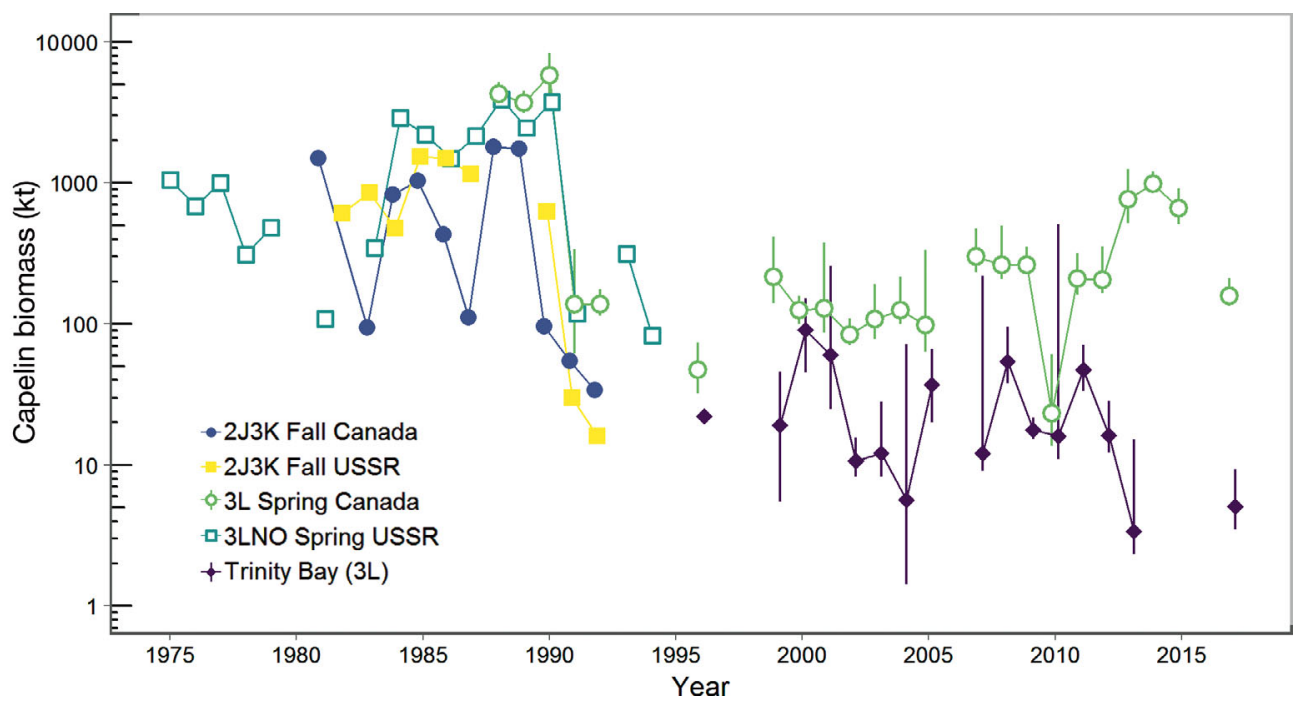

Fig. 2. Trends in biomass of capelin determined by 5 acoustic survey indices: Divs. 2J3K Fall Canada (19821992), Divs. 2J3K Fall USSR (1982-1992), Div. 3L Spring Canada (1988-1992, 1996, 1999-2005, 2007-2015, 2017), Divs. 3LNO Spring USSR (1975-1994), and Trinity Bay (inshore Div. 3L; 1999-2005, 2007-2013, 2017). Vertical lines: $95 \%$ confidence intervals of the index. A Monte Carlo approach to calculate confidence intervals was only used on Div. 3L Spring Canada data (Mowbray 2014). Note the log scale

in Div. 3L and provided an annual index of capelin abundance recruiting into the fished population the following year (Mowbray 2014). In the Canadian spring acoustic survey, capelin biomass decreased 2 orders of magnitude from a high of $6 \mathrm{Mt}$ in the late 1980s to $0.02 \mathrm{Mt}$ in 2010 (Mowbray 2014) (Fig. 2). While there has been an increase in capelin biomass in recent years (0.7-1.0 Mt in 2013-2015), capelin biomass overall has remained persistently low since 1990-1991 (DFO 2018). Capelin is currently acoustically surveyed in the spring in Div. 3L by Canada with the discontinuation of the 3 other acoustic surveys in the early 1990s (Canada fall acoustic survey in 1994; former USSR fall and spring acoustic surveys in 1992 and 1994, respectively).

While the offshore acoustic surveys provided strong evidence of a capelin collapse, they did not cover the inshore area. The non-collapse hypothesis used observations of overwintering maturing capelin and large schools of immature capelin during winter surveys conducted in Trinity Bay in 1967-1968 (Winters 1970) as evidence that significant densities of capelin can inhabit the inshore area year-round. The hypothesis of year-round inshore residency of capelin was tested by conducting seasonal acoustic surveys and expanding the annual offshore spring acoustic survey into Trinity Bay (Fig. 1). Seasonally in the main portion of Trinity Bay, capelin densities were zero in January and moderate in May (Fig. 3a). The maximum mean density of capelin was observed in June 2004 (10720 kg km²), which corresponded with the start of the spawning period when capelin were highly aggregated inshore (Fig. 3a). In September and October, capelin densities were low once again (Fig. 3a). There was also a distinct seasonal pattern in
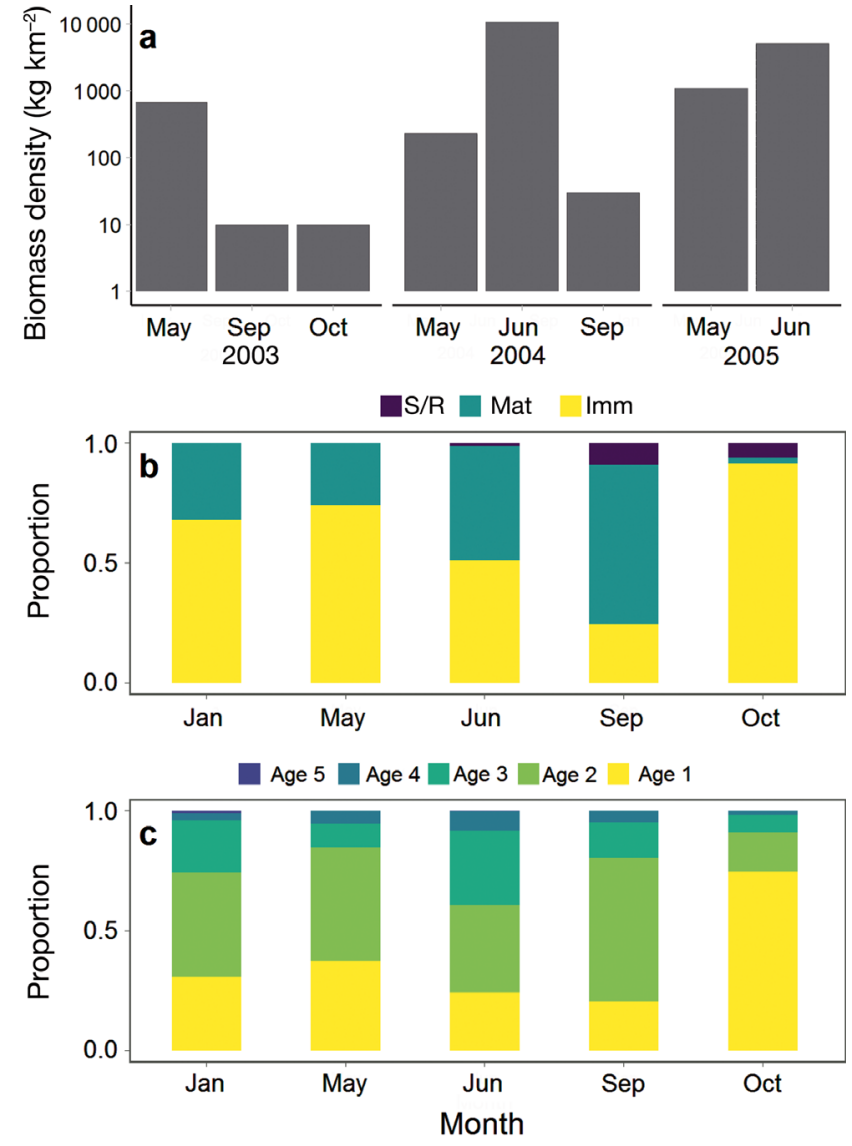

Fig. 3. (a) Capelin mean density $\left(\mathrm{kg} \mathrm{km}^{-2}\right)$ estimated from the seasonal inshore acoustic surveys of the main portion of Trinity Bay, NL, Canada (2003-2005). Note the log scale; capelin mean density was zero in January 2004-2005 and September 2005 and these data were not included due to the log scale. (b) Capelin maturity stage composition $(\mathrm{n}=5319)$, and (c) age composition ( $\mathrm{n}=864$ ) sampled in the seasonal inshore acoustic surveys of the main portion of Trinity Bay and the arms. S/R: spent/recovering; Mat: maturing; Imm: immature 
the age and maturity composition inshore, using samples from both the main bay and the arms. In January, overwintering fish were composed of $\sim 70 \%$ immature age- 1 and age-2 fish (Fig. 3b,c); the relative contribution of older fish increased through the spring as maturing age- 2 and age- 3 fish migrated into Trinity Bay (Fig. 3b,c); and by October, immature age-1 fish dominated the inshore area, strongly suggesting that spent mature fish had either died or left the Bay (Fig. 3b). In agreement with this finding, an inshore acoustic survey in January 2000 for overwintering Atlantic cod from Conception Bay to Notre Dame Bay found concentrations of juvenile capelin (O'Driscoll \& Rose 2001) but few older fish (G. A. Rose unpubl. data). These seasonal surveys found no evidence of a large inshore, non-migratory capelin stock.

The non-collapse hypothesis was also tested by investigating the spatial distribution of capelin in years when the annual offshore spring acoustic survey included an inshore component (Fig. 2). Capelin biomass inshore and offshore in May was weakly negatively correlated but non-significant (Pearson correlation: $\mathrm{R}=-0.22, t=$ -0.83 , df $=14, \mathrm{p}=0.42$ ). In the majority of years, $>90 \%$ of surveyed capelin biomass was offshore (Fig. 2). In 4 of the 14 years $(2000,2001,2005$, and 2010), 27$42 \%$ of the total capelin biomass surveyed was inshore (Fig. 2). A significant portion of the capelin population inshore in some years provides support for the non-collapse hypothesis. However, a simple calculation indicates that it is unrealistic to assume that 3-6 Mt of capelin that have been 'missing' in the offshore surveys since 1990 are now residing in the inshore. The mean density for 3-6 Mt of capelin undetected in approximately $71000 \mathrm{~km}^{2}$ of poorly surveyed and un-surveyed inshore waters (i.e. Fig. 4, both the red and pink areas) would have to average between 42000 and $84000 \mathrm{~kg} \mathrm{~km} \mathrm{~km}^{-2}$. The maximum mean density of capelin observed in the Trinity Bay seasonal acoustic survey was 10720 kg km-2 in June 2004 when capelin were highly aggregated inshore, and the mean density of capelin inshore outside of the spawning period was $\sim 40 \mathrm{~kg}$ $\mathrm{km}^{-2}$ (Fig. 3a). Overall, these analyses indicate it is unlikely that the Div. 2J3KL capelin stock became non-migratory and remained inshore since 1990.
In summary, while the fall and spring acoustic surveys in Divs. 2J3KLNO support the capelin collapse hypothesis, data from the acoustic surveys cannot refute the hypothesis that capelin became nonmigratory post-1990 as inshore areas were not systematically surveyed. However, the sheer density of fish required to compensate for the 'missing' 3-6 Mt of capelin offshore (42000-84 $000 \mathrm{~kg} \mathrm{~km}^{-2}$ on average) is staggering and was never detected by the seasonal inshore acoustic surveys. Thus, inshore and offshore acoustic surveys in combination with the simple density calculation provide strong support for the capelin collapse hypothesis (Table 1).

3.1.2. Offshore capelin distribution: annual multi-species bottom-trawl surveys

The CG and I analyses based on Woillez et al. (2007) did not support the hypothesis that capelin shifted their distribution toward the inshore in 1990-

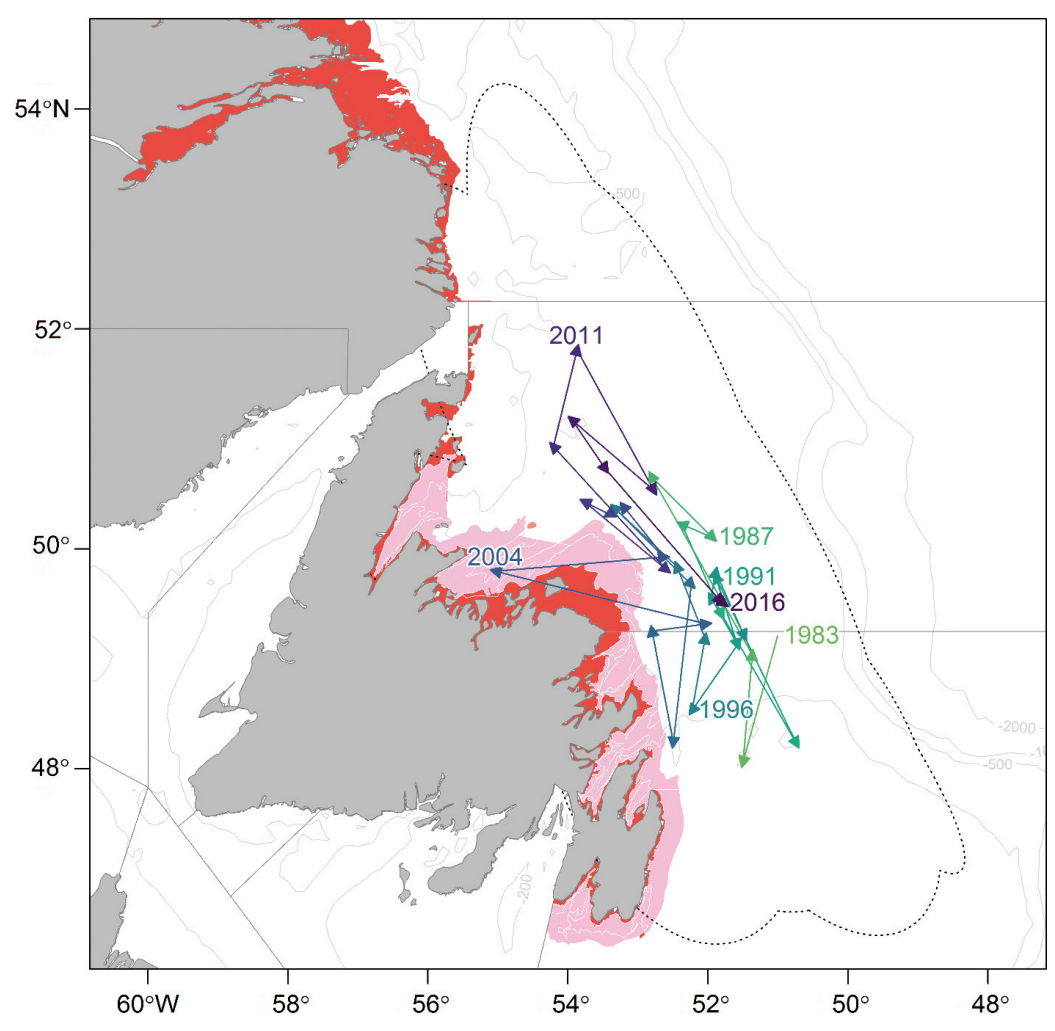

Fig. 4. Distribution of the center of gravity (CG) of capelin computed from the fall bottom-trawl survey in Northwest Atlantic Fisheries Organization (NAFO) Divisions 2J3KL from 1983 to 2016. Annual CG estimates are connected by lines through time, and composite ellipses of deviation around these estimates (i.e. inertia) are indicated by the dotted black line. CG and inertia were calculated using equations found in Woillez et al. (2007). Red shading: areas not covered by the survey; light pink shading: inshore strata that are poorly covered by the fall bottom-trawl survey 
Table 1. Differing degrees of support that each line of evidence provides for the capelin collapse and non-collapse hypotheses. Degrees of support are categorized into 6 classes: $(++)$ support in favor of hypothesis; $(+)$ consistent with hypothesis; (=) equivocal support; $(-)$ inconsistent with hypothesis; $(--)$ support against hypothesis; $(\times)$ evidence cannot be used to test the hypotheses

\begin{tabular}{|lcc|}
\hline Evidence & $\begin{array}{c}\text { Collapse } \\
\text { hypothesis }\end{array}$ & $\begin{array}{c}\text { Non-collapse } \\
\text { hypothesis }\end{array}$ \\
\hline Offshore capelin abundance & ++ & -- \\
Inshore density estimate of 'missing' offshore capelin & ++ & -- \\
Offshore capelin distribution & ++ & - \\
Timing of capelin offshore residence & ++ & - \\
Independent indices of inshore capelin abundance & $\times$ & $\times$ \\
Inshore recruitment index & + & - \\
Temporal dynamics of cod weight-at-age and condition & + & - \\
Harp seal population trends and diet & + & - \\
Seabird population trends and diets & $=$ & $=$ \\
Zooplankton response: Calanus finmarchicus abundance & $\times$ & $\times$ \\
Physical variability & + & - \\
\hline
\end{tabular}

1991 and remained inshore for the subsequent 3 decades (Figs. 4 \& S3-S5). The FBTS survey coverage has been consistent over the past 4 decades so the effect of shifting survey coverage on the CG estimate was expected to be minimal (Fig. S4). The CG trend in most decades was a pronounced shift along the north-south axis rather than the east-west axis, with an exception in the 2000s when there was a westward shift in the CG (Fig. 4). In the 2010s, the CG was again offshore with shifts along the north-south axis, similar to the CG of the late 1980s (Fig. 4). Like the acoustic surveys, the FBTS has poor survey coverage of the inshore. It is, therefore, possible that significant inshore aggregations of capelin could go undetected. However, if significant capelin aggregations were present inshore, then the CG would be oriented toward the inshore during years when more inshore strata were surveyed (1996-1998, 20002002, 2004-2006, 2010, 2013). Instead, the CG was oriented toward the inshore only in the 2000s (Fig. 4).

There has been a bias for increased catches of capelin in the FBTS since 1995, not only due to a change in sampling gear but also due to a change in habitat use of capelin (Mowbray 2002). Since 1991, capelin diel vertical migratory behavior changed with deeper distributions below the cold intermediate layer $(\sim 200 \mathrm{~m})$ and in closer association with the bottom (peak density $\sim 20 \mathrm{~m}$ off bottom), with capelin rarely found in the upper $50 \mathrm{~m}$ of the water column (Mowbray 2002). This change in behavior may be in response to a decline in the risk of groundfish (e.g. Atlantic cod) predation that may drive capelin into the pelagic zone (Rose 1993, McQuinn 2009). Due to the inherent biases in the
FBTS data, other data sources were considered to investigate the center of distribution of capelin post-1990 (sensu Jech \& McQuinn 2016). Juvenile capelin surveys using an International Young Gadoid Pelagic Trawl (IYGPT) in the northeastern bays and the offshore from 1994-1999 found centers of distribution of capelin juveniles on the northern Grand Bank and along the northeast coast, but not in the bays of Newfoundland (Anderson et al. 2002). This is consistent with capelin migrating to their nursery areas in the offshore. Thus, this independent study of juvenile capelin distribution supports the CG analysis using the FBTS data.

In summary, capelin distribution moved predominately along the north-south axis rather than the east-west axis post-1990 based on a CG analysis that accounted for both $I$ (i.e. spatial dispersion of the population around its CG) and changes in FBTS sampling effort. The CG analysis does not support the hypothesis of inshore residence of capelin since 1990-1991, and, in combination with the finding that the center of juvenile capelin distribution was also offshore in the 1990s, supports the collapse hypothesis (Table 1).

\subsubsection{Residence time of capelin concentrations during offshore acoustic surveys in Div. 3L}

The non-collapse hypothesis assumed that the delay in the timing of capelin spawning since 1991 led to a mismatch in capelin availability to the spring acoustic survey, which has resulted in the spring acoustic survey severely underestimating capelin biomass offshore. Since 1991, capelin spawning has been persistently delayed on average by 4 wk (DFO 2018). Meanwhile, the spring acoustic survey has been fixed spatially and temporally since the 1980s, which raises the possibility that the spring acoustic survey may not monitor migrating capelin consistently post-1990. However, it is important to note that the spring acoustic survey, which encompasses a capelin nursery area, was primarily designed to survey the non-migratory, immature portion of the stock, rather than the spawning 
migration (Mowbray 2014). All age classes acoustically surveyed are included in the annual index of capelin abundance, but the spring acoustic survey does not target capelin spawning migrations, and therefore should not be considered as a proxy for spawning stock biomass.

While a delay in the timing of spawning should not have a direct impact on the acoustic abundance index derived from the spring acoustic survey, earlier maturation could alter the age structure of the observed stock component. Specifically, since there is inter-annual variability in the proportion of age-2s starting their adult migration patterns and the spring acoustic survey does not target spawning migrations, this stock component may be under-represented in the survey. The proportion of mature age- 2 capelin in the spring acoustic survey has increased since 1991 (4\% pre-1991 compared to $37-79 \%$ since 1991) (Mowbray 2014, DFO 2018). In the Barents Sea, capelin growth may be stock-abundance dependent, with faster juvenile growth observed when the stock size is small; and since timing of maturation is linked to growth, year classes with fast juvenile growth mature earlier (reviewed in Gjøsæter 1998). For the Div. 2J3KL capelin stock, growth of age-2 capelin has been faster post1990 (DFO 2018), which provides support for the collapse hypothesis (i.e. smaller stock size post-1990) and may explain the persistently earlier maturation of capelin since 1991. Despite the earlier observed maturation of capelin since 1991, there has been high internal consistency in the spring acoustic survey, with the index of abundance for the age-3 cohort being strongly correlated with the index of abundance for the age-2 cohort from the previous year (DFO 2018). This result implies that the spring acoustic survey captures relative changes in the overall stock, regardless of the proportion of migrating/non-migrating individuals.

If there was a significant inshore capelin population post-1990, this change in population demographics should be reflected in both the inshore commercial catch and the offshore acoustic survey. Prior to 1991, mature age-2 capelin were a negligible component of the inshore commercial fish- ery $(<5 \%$ of total catch) (Fig. 5) (DFO 2018). Since 1991, the contribution of mature age- 2 capelin increased to almost half of commercial inshore catches (Fig. 5) (DFO 2018), which is consistent with earlier maturation. The age structure of offshore catches is not consistent with the non-collapse hypothesis, as the proportion of age- 2 and age- 3 fish sampled offshore has remained constant pre- to post1990 at $\sim 60 \%$ and $\sim 28 \%$ of the catch, respectively (DFO 2018). Furthermore, the increased proportion of mature age-2 fish in the inshore catch post-1990 can be explained by the increase in proportion of age-2 fish maturing offshore and undergoing a spawning migration, rather than an absence of migration per se.

In summary, neither the persistent delay in spawning time nor earlier maturation of capelin since 1991 seem to significantly impact the ability of the spring acoustic survey to provide a relative index of capelin abundance. Data from the spring acoustic survey supports the capelin collapse hypothesis (Table 1).

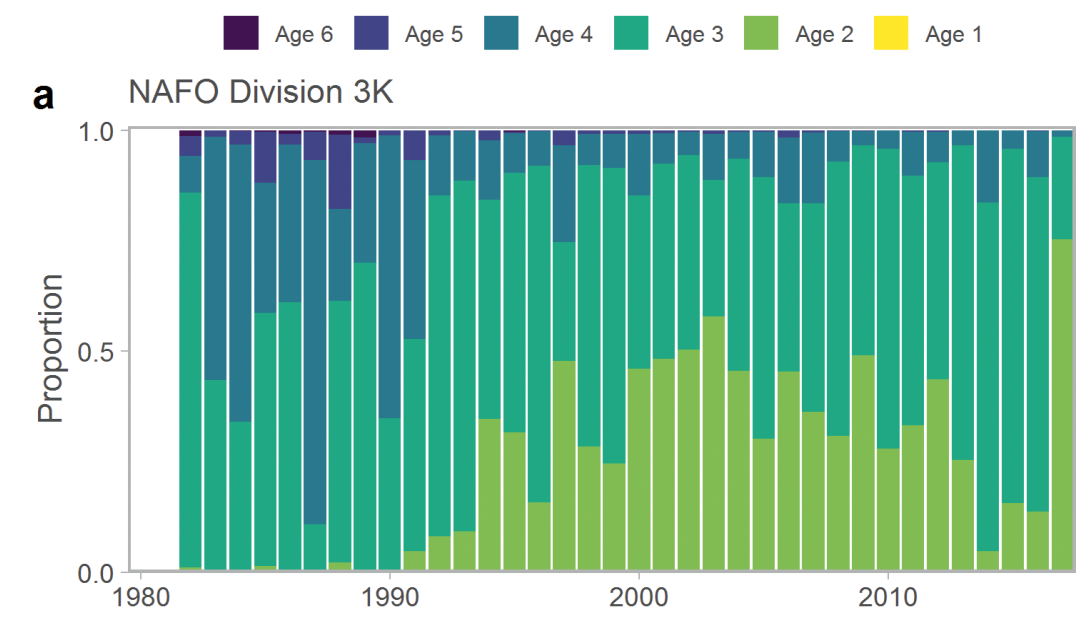

b NAFO Division $3 L$

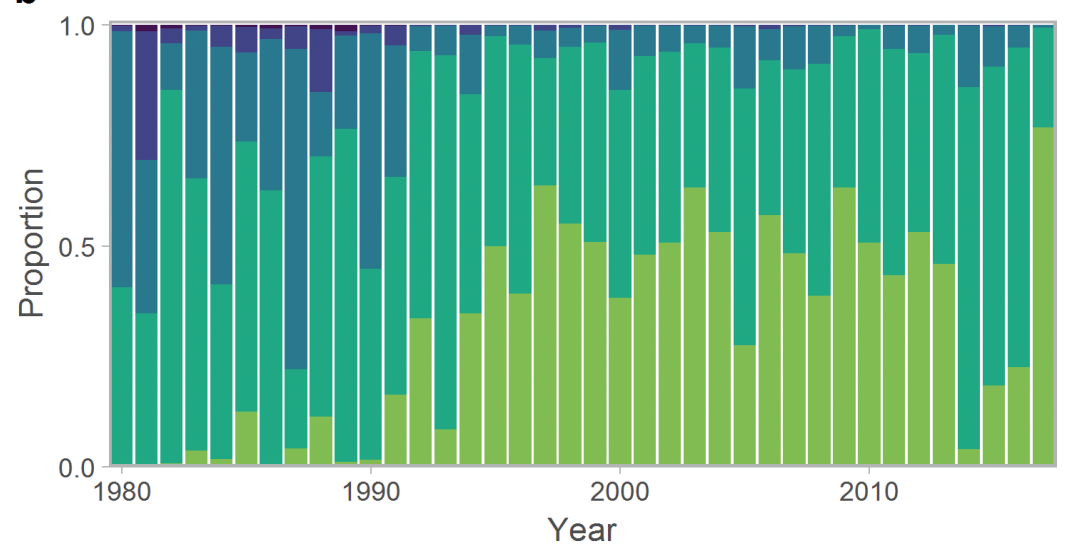

Fig. 5. Age composition of capelin landed in the commercial inshore fishery in Northwest Atlantic Fisheries Organization (NAFO) Divs. (a) 3K and (b) 3L for the years 1980-2017 


\subsubsection{Independent indices of inshore capelin} abundance

Two inshore indices collected by DFO during the 1980s and 1990s were an aerial abundance index and inshore commercial catch rates. The non-collapse hypothesis implied that strong correlations between these 2 independent inshore indices post-1990 in addition to no obvious decrease in these indices between the late 1980s and the early 1990s was supportive of a stable stock. The aerial survey was designed to estimate capelin spawning stock biomass based on the area of capelin schools near spawning beaches in Div. 3L (Nakashima 1997). The aerial survey commenced in 1982, and initially followed 4 defined survey tracks in Conception and Trinity Bays during a fixed period of mid-June to early July (Carscadden et al. 1994). Protracted spawning since 1991 violated a key assumption of the aerial surveys: all spawning fish must arrive at the same time in each bay to form a single spawning peak. Protracted spawning from early July to mid-August in 19911993 resulted in multimodal capelin spawning peaks that were covered with variable success by the aerial survey (Nakashima 1996). For example, in 1993, the peak spawning period was adequately surveyed in Conception Bay, but 2 spawning peaks in Trinity Bay, based on the egg deposition index, were missed (Nakashima 1996). In 1997, the geographical coverage of the aerial survey was reduced to 2 transects in the inner areas of Trinity and Conception Bays (Anon 1998). While the estimated aerial abundance index in 1997 was fourth highest in the time series, there were concerns that the limited geographical coverage of the aerial survey did not accurately reflect the status of the stock (Anon 1998). Indeed, 5 of the 8 years of aerial data since 1991 did not adequately cover peak spawning times (1991-1993) and had reduced geographical coverage (1997-1998). The aerial survey was discontinued in 1999 due to lack of funding.

Although considered an index of capelin spawning stock biomass during the 1980s, the inshore commercial catch rate data have not been included in the Div. 2J3KL capelin stock assessment process since 1993 due to changes in management regulations. As a consequence of the small sizes of spawning capelin post-1990, management regulations introduced a size criterion of 50 capelin $\mathrm{kg}^{-1}$ to reduce dumping of undersized capelin (Carscadden \& Nakashima 1997). This size criterion effectively closed the fishery in 1994 and 1995. From 1996, the size criterion was removed but management regulations to reduce discarding of small, unmarketable capelin resulted in fishing effort being concentrated to a few days when large capelin were available (Anon 1998). Post-1990, the inter-annual variability in participation in the fishery due to fish quality and market forces resulted in overall fishing effort being reduced and concentrated to when capelin were available, resulting in high catch rates which rendered the inshore catch rate index useless as an indicator of stock abundance (Anon 1998).

In summary, due to changes in capelin biology and management measures post-1990, neither inshore index provides reliable data on spawning stock biomass. Therefore, these indices should not be used to support or refute either hypothesis (Table 1).

\subsubsection{Inshore recruitment index}

Capelin larval production in August in Trinity Bay did not change appreciably between years prior to and since 1991, which was used as support for the non-collapse hypothesis. DFO collects 2 larval indices in Trinity Bay: an emergent larval index (3$10 \mathrm{~mm}$ standard length, SL) in a nearshore area and a late-larval index (10-30 mm SL) collected in the middle of the bay (see Nakashima \& Mowbray 2014 for more details). Given the persistently later capelin spawning since 1991, it is appropriate to compare late-larval densities in August in years pre-1991 to September in years since 1991 in order to compare productivity of similar larval developmental stages (Nakashima \& Mowbray 2014). Late-larval densities in September since 1991 were consistently lower and more variable than in August pre-1991: average $( \pm$ SD) late-larval density in Trinity Bay in September 2002-2015 was $30.9 \pm 26.9 \mathrm{~m}^{-2}$ (range: $6.7-97.0 \mathrm{~m}^{-2}$ ) and in August 1982-1986 was $48.8 \pm 15.1 \mathrm{~m}^{-2}$ (range: 33.2-73.6 $\mathrm{m}^{-2}$ ) (Fig. 6). The substantial decrease in larval productivity since 1991 is consistent with the capelin collapse hypothesis.

The emergent larval index was related to the age2 abundance index from the spring acoustic survey, which was lagged by $2 \mathrm{yr}$ in order to compare survivors of the same cohort (Murphy et al. 2018). The positive, significant relationship between 2 fisheryindependent inshore and offshore indices since 1991 supports previous research that identified early larval survival as an important driver of capelin recruitment (Frank \& Leggett 1982, Leggett et al. 1984, Dalley et al. 2002). This result suggests that the offshore spring acoustic survey tracks inshore larval productivity, supporting the capelin collapse hypothesis. While it is possible that the offshore age-2 capelin 


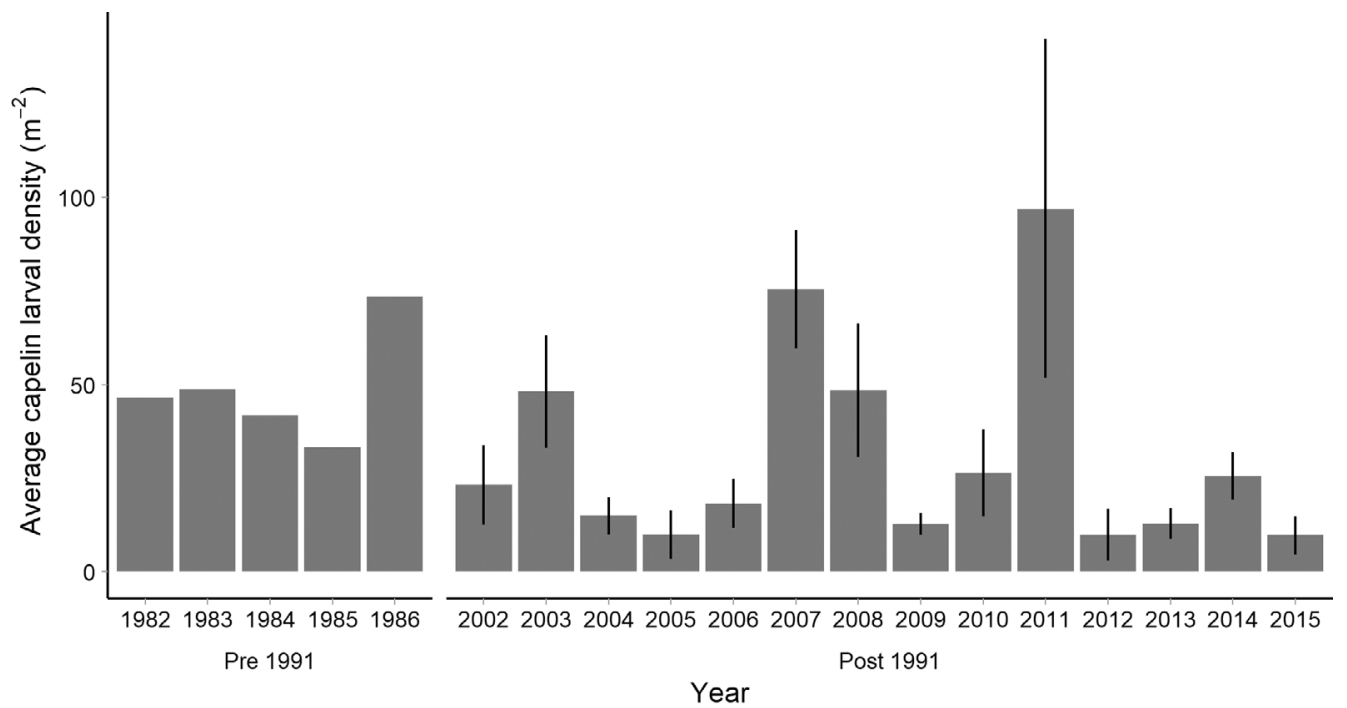

abundance index reflects an overflow or spillover of age- 2 capelin in proportion to inshore productivity, the inshore acoustic seasonal surveys did not find a significant inshore population of capelin outside of the spawning period.

In summary, comparing larval productivity in August pre-1991 and September since 1991 in combination with the significant relationship between 2 fishery-independent inshore and offshore indices post-1990 concurs with the collapse hypothesis (Table 1).

\subsection{Ecosystem response}

\subsubsection{Temporal dynamics of cod weight-at-age and condition}

From the early 1980 s to the late 1990 s, the condition and weight-at-age of Atlantic cod in Divs. 2J3KL (also known as 'northern' cod) declined markedly in the northern portion of its range (Div. 2J) with a similar declining trend in Div. 3K. Condition indices remained relatively unchanged in the southern portion of Atlantic cod's range (Div. 3L). Weight-at-age of 4 and $5 \mathrm{yr}$ old Atlantic cod actually increased slightly in the mid-1990s in Div. 3L but later declined to the post-1990 average (Frank et al. 2016). This increase in weight-at-age in Div. 3L during the mid1990s was considered support for the non-collapse hypothesis.

The increase in Atlantic cod weight-at-age and condition in Div. 3L in the mid-1990s may have been due to a shift in spatial distribution of both capelin and Atlantic cod. During and post-1991, capelin shifted its fall distribution from having 2 distinct aggregations, one in the northwest (Divs. 2J3K) and one in the southeast (Div. 3L, at the northern slope of the Grand Bank), to having only one in the southeast (Lilly \& Davis 1993, Miller 1994), with records of excursions of capelin onto the Flemish Cap and the Scotian Shelf (Frank et al. 1996). Coincidently, Atlantic cod moved southward on the northeast Newfoundland shelf in the late 1980s and early 1990s and aggregated within a small area on the northern Grand Bank and in the Bonavista Corridor (Rose 1993, Rose et al. 2000). Rose et al. (2000) hypothesized that the observed shift in Atlantic cod distribution was a response to the southerly distribution of capelin observed post-1990. Atlantic cod's weight-atage and liver condition worsened in northerly areas where there was no spatial overlap between Atlantic cod and capelin, and remained relatively stable in southerly areas where the collapsed Atlantic cod stock overlapped with capelin.

The existence of spatial structure in condition traits of Atlantic cod is not unique to the early 1990s and has been documented extensively (Rose \& Rowe 2018), with historical latitudinal gradients in growth (length-at-age) and condition indices (liver, gutted and total body mass) (Buren et al. 2014b, Morgan et al. 2018). Atlantic cod weight-at-age and liver condition indices have never been spatially homogenous due to the species complex inhabiting distinct ecosystem production units in Divs. 2J3KLNO (e.g. Lilly 2005, Koen-Alonso et al. 2013, Morgan et al. 2018). These units are characterized by distinct marine communities and food web systems (Koen-Alonso et 
al. 2013, NAFO 2014, Pepin et al. 2014). Therefore, the non-homogenous traits of Atlantic cod from Labrador (Div. 2J) to the southern Grand Bank (Divs. $3 \mathrm{NO}$ ) are typical of this stock complex and cannot be used to support the non-collapse hypothesis.

In summary, the lack of change in Atlantic cod condition in Div. 3L in the 1990s does not support the non-collapse hypothesis as Atlantic cod condition is associated with spatial overlap of capelin (Table 1). Atlantic cod condition was worse in Divs. 2J3K where capelin were no longer observed post-1990 compared to Atlantic cod in the south (Div. 3L) where the capelin population had contracted.

\subsubsection{Harp seal population trends and diet}

Large numbers of starving harp seals were observed following the collapse of capelin in the Barents Sea in the mid-1980s (Haug \& Nilssen 1995). The absence of an obvious response in Northwest Atlantic harp seal populations to the proposed collapse of the Div. 2J3KL capelin stock in 1990-1991 was considered support for the non-collapse hypothesis. However, there are significant differences between the 2 regions, and predator populations can be expected to respond differently in the 2 areas. In the Barents Sea, the collapse of capelin during the mid1980s occurred when the stocks of other energy-rich forage fish, including Atlantic herring and Arctic cod Boreogadus saida, were severely depleted (Hamre 1994, Hop \& Gjøsæter 2013). Therefore, the effects of the capelin collapse were amplified and reached several taxa including Atlantic cod, seals, and seabirds (Hamre 1994). Barents Sea capelin declined in 19921993 without a similar occurrence of starving seals, which was likely due to the availability of alternative prey (Atlantic herring and Arctic cod; Nilssen et al. 1998). In the Northwest Atlantic, Arctic cod and Atlantic herring were available as prey for harp seals during the early 1990s (e.g. Bourne et al. 2015), as indicated by the large proportional increase of these alternate prey in harp seal diets during this period (Stenson 2012).

While Northwest Atlantic harp seals did not show catastrophic mortalities post-1990, they have been impacted by the decline in capelin. Until the late 1970 s, pregnancy rates were consistently around $85 \%$. Since then, pregnancy rates have been highly variable (ranging from 20-75\%) with an overall declining trend (Stenson et al. 2016). In addition, late-term abortions have become a regular occurrence since the late 1980s. Stenson et al. (2016) found that while the general decline in harp seal fecundity reflected density-dependent processes associated with increased population size, including the late-term abortion rates in their model allowed them to explain the large inter-annual variability in pregnancy rates. Changes in the abortion rates, in turn, were found to be influenced by ice cover in late January and capelin biomass. Buren et al. (2014a) found that capelin abundance is associated with ice conditions, suggesting that late January ice conditions reflect changes in environmental conditions that influence many prey species. While higher catches in the Canadian commercial seal hunt from 1996-2008 contributed to reductions in the rate of harp seal population growth, lower pregnancy rates also had a major impact on the dynamics of this population. This is evident in the past decade where the commercial catches have declined but there has not been a concomitant increase in harp seal population abundance.

In summary, the absence of starving seals post1990 does not indicate that the Div. 2J3KL capelin stock remained stable and did not collapse (Table 1). However, a declining trend in pregnancy rates and an increase in late-term abortions, which was related to capelin abundance, suggest that a collapsed Div. 2J3KL capelin stock has been a limiting factor in harp seal fecundity during the past 3 decades.

\subsubsection{Seabird population trends and diets}

Populations of common murres Uria aalge, Atlantic puffins Fratercula arctica and northern gannets Morus bassanus off eastern Newfoundland increased in the 1990s (Chardine et al. 2003). Given that capelin is an important prey item for these predators, particularly during the breeding season, increases in their populations appear to be inconsistent with the collapse hypothesis.

Fish stocks in general (e.g. Atlantic cod, Rose \& Kulka 1999) and pelagic stocks in particular (e.g. Northwest Atlantic herring stocks, Winters \& Wheeler 1985) contract their geographic range during periods of rapid population decline (Winters \& Wheeler 1985, Burgess et al. 2017). Capelin's CG contracted southward during the 1990s and moved inshore in the 2000 s i.e. nearer the vicinity of seabird colonies along Newfoundland's northeast coast (Fig. 4). Throughout the 1990s and 2000s, common murres on Funk Island fed capelin almost exclusively to their chicks during the breeding season (Davoren \& Montevecchi 2003, W. A. Montevecchi pers. 
comm.). Consistently high local abundances of capelin at annually persistent spawning sites within seabird foraging ranges allowed for the high percentage of capelin in parental deliveries (Davoren et al. 2012, Davoren 2013). Therefore, a higher proportion of capelin in common murre's diet post-1990 is not inconsistent with the collapse hypothesis, whereby the range of the collapsed Div. 2J3KL capelin stock overlapped with the foraging range of seabird breeding colonies.

Capelin also represented significant proportions of northern gannet's diet from 1990-2012 (20-100\%) in contrast to pre-1990 (<12\%; Montevecchi 2007, Bennett et al. 2013). This change in northern gannet diet was proposed as support for the non-collapse hypothesis. However, this change in diet occurred at the same time as the cold-water intrusion of the early 1990s that was associated with a decline in the abundance of northern gannet's preferred migratory warm-water large pelagic prey (mackerel Scomber scombrus, Atlantic saury Scomberesox saurus, and short-finned squid Illex illecebrosus) (Montevecchi \& Myers 1997, Montevecchi 2007). For example, when mackerel and saury were more abundant in the region in 2005 and 2006 when waters were warmer, the percentage of capelin in the northern gannets' prey landings fell to $13 \%$ and $2 \%$ (Montevecchi 2007). In addition, the lack of capelin in seabird diets during the 1990s in Labrador (Bryant \& Jones 1999, Baillie \& Jones 2004) is inconsistent with the non-collapse hypothesis.

Increases in seabird populations post-1990 were attributed to factors unrelated to capelin availability. For example, the population increase of common murres post-1990 has been associated with major reductions in adult mortality due to the coincident closure of the Atlantic salmon Salmo salar and Atlantic cod gillnet fisheries (Regular et al. 2013). The removal of thousands of gillnets from inshore areas during the 1990s and 2000s resulted in a significant reduction in bycatch mortality of breeding adult diving seabirds. Reductions in common murre adult mortality associated with ship-sourced oil pollution and hunting also decreased during this same period (Wilhelm et al. 2009). Increases in the populations of Atlantic puffins and northern gannets in the 1990s and 2000s were also associated with these factors.

In summary, the trends in seabird abundance do not provide support for either the collapse or non-collapse hypothesis as other variables, such as removal of gillnets in the inshore area, had a larger impact on breeding adult seabird survival (Table 1). Seabird dietary information does not provide support for either hypothesis, but seabird diet did reflect the late inshore arrival of capelin post-1990 (Davoren \& Montevecchi 2003, Gulka et al. 2017) and is consistent with changes in availability of various prey.

\subsubsection{Zooplankton response: Calanus finmarchicus abundance}

Given the magnitude of the capelin collapse, a significant increase in their main copepod prey, Calanus finmarchicus, might have been expected (e.g. Gjøsæter et al. 2002). Unlike the extensive zooplankton sampling effort in the Barents Sea, zooplankton on the NL shelf (Divs. 3KL) have only been sampled on a regular basis using plankton nets since 1999 (DFO's Atlantic Zone Monitoring Program). The Continuous Plankton Recorder (CPR) data set, which commenced in the late 1950s, was used to test the non-collapse hypothesis. However, the usefulness of CPR data in tracking inter-annual changes in copepod abundance in the Northwest Atlantic has been questioned. Head \& Pepin (2010) noted that only 2 years between 1960 and 1978 had more than 8 mo of observations over the Grand Bank sections of the CPR sampling, which was the section used to test the non-collapse hypothesis, and inconsistencies in the course of the survey tracks from ships-of-opportunity resulted in uneven sampling of different water masses (Pepin et al. 2011). There was a substantial reduction in CPR mileage towed in the 1980s with a contraction of monitoring to $20^{\circ} \mathrm{W}$ in the eastern Atlantic (Reid et al. 2003); consequently, there are large gaps in monthly CPR data from 1979-1990, particularly between 1986 and 1990, which precluded its use in a recent capelin study (Mullowney et al. 2016).

In summary, CPR data cannot be used to support either hypothesis (Table 1).

\subsubsection{Physical variability}

The non-collapse hypothesis used an analysis of ocean climate to show a change in environmental conditions $\sim 5$ yr after the proposed capelin collapse and concluded that the physical evidence for an environmental driver of capelin collapse was weak. Elsewhere in the literature, 1991, not 1996, has been identified as a climatologically important decadal signal due to its strong cold anomaly (e.g. Drinkwater 1996, Colbourne et al. 2016). The cold anomaly in 1991 was associated with a regime shift in the North- 
west Atlantic ecosystem that was characterized by the collapse of capelin and other commercial and non-commercial finfish species and correspondent increase in shellfish biomass (Lilly et al. 2000, Buren et al. 2014a, Pedersen et al. 2017), seabird dietary shifts from warm- to cold-water pelagic prey (Montevecchi \& Myers 1997, Montevecchi 2007), and shifts in groundfish diet (Dawe et al. 2012).

In summary, this study's findings show evidence of a capelin collapse that coincided with a regime shift, which is consistent with other studies that attributed ecosystem-wide changes in the NL region to the cold-water anomaly in 1991 (Table 1).

\section{DISCUSSION}

The weight of evidence led us to conclude that the Div. 2J3KL capelin stock suffered a population collapse in 1990-1991 with minimal recovery in the subsequent 3 decades. We found strong internal and external consistency in trends across multiple independent sources of data (Table 1). In particular, the spring acoustic survey effectively tracked capelin year classes and was strongly correlated with an independent inshore larval abundance survey. Moreover, we found strong agreement across independent acoustic surveys conducted in offshore waters. These acoustic surveys supported the scenario of a capelin stock collapse in the early 1990s, and subsequent surveys and data examined were not consistent with the possibility that millions of tonnes of capelin have been residing along the northeast coast of NL for almost 3 decades. Our conclusion is thus consistent with that of numerous past studies that concluded that the Div. 2J3KL capelin stock suffered an order of magnitude decline in the early 1990s (DFO 1994，2008，2010，2013，2015，2018, Miller 1994, 1997, Rose \& O'Driscoll 2002, Davoren \& Montevecchi 2003, Buren et al. 2014a, Mullowney \& Rose 2014, Murphy et al. 2018).

In contrast, the non-collapse hypothesis postulated that the Div. 2J3KL capelin stock did not suffer a collapse but instead experienced a dramatic change in phenology post-1990, which reduced their vulnerability to existing surveys. Specifically, the non-collapse hypothesis states there was either (1) a spatiotemporal mismatch between the spring acoustic survey and capelin phenology or (2) a change in the ecology of capelin from a highly migratory stock to one that resides year-round within poorly surveyed inshore waters. The first hypothesis was rejected both by Frank et al. (2016) and our analyses. From our test of the second hypothesis proposing the inshore residence of 3-6 Mt of capelin, we concluded that there would have to be on average between $42000-84000 \mathrm{~kg} \mathrm{~km}^{-2}$ of capelin to compensate for the 'missing' offshore fish. Instead, seasonal inshore acoustic surveys in Trinity Bay revealed a maximum mean capelin density of $10720 \mathrm{~kg} \mathrm{~km}^{-2}$ in June, and much lower densities outside of the peak spawning period. Most importantly, we conclude that it is not plausible that 3-6 Mt of capelin distributed inshore would have gone unnoticed for 3 decades by DFO, academic researchers, and fish harvesters from the numerous fishing communities that span the northeast coast of NL.

Acknowledgements. We acknowledge the constructive comments of E. J. Pedersen, 3 anonymous reviewers and the Editor. None of the authors have a conflict of interest to declare.

\section{LITERATURE CITED}

Anderson JT, Dalley EL, O'Driscoll RL (2002) Juvenile capelin (Mallotus villosus) off Newfoundland and Labrador in the 1990s. ICES J Mar Sci 59:917-928

Anon (1998) Capelin in SA2 + Div. 3KL. DFO Can Stock Assess Sec Res Doc 98/63

Baillie SM, Jones IL (2004) Response of Atlantic puffins to a decline in capelin abundance at the Gannet Islands, Labrador. Waterbirds 27:102-111

* Bakanev VS (1992) Results from the acoustic capelin surveys in Div. 3LNO and 2J+3KL in 1991. NAFO SCR Doc 92/1

Bennett SG, Burke CM, Hedd A, Montevecchi William A (2013) Comparison of capelin Mallotus villosus in the prey loads of common murres Uria aalge and northern gannets Morus bassanus foraging from the same breeding site in the Northwest Atlantic. Mar Ornithol 41: 179-182

Bourne C, Mowbray F, Squires B, Croft J (2015) An assessment framework and review of Newfoundland east and south coast Atlantic herring (Clupea harengus) stocks to the spring of 2013. DFO Can Sci Advis Sec Res Doc 2015/029

Brodie W (2005) A description of the autumn multispecies surveys in SA2+ Divisions 3KLMNO from 1995-2004. NAFO SCR Doc 05/8

Bryant R, Jones IL (1999) Food resource use and diet overlap of common and thick-billed murres at the Gannet Islands, Labrador. Waterbirds 22:392-400

* Buren AD, Koen-Alonso M, Pepin P, Mowbray F and others (2014a) Bottom-up regulation of capelin, a keystone forage species. PLOS ONE 9:e87589

Buren AD, Koen-Alonso M, Stenson GB (2014b) The role of harp seals, fisheries and food availability in driving the dynamics of northern cod. Mar Ecol Prog Ser 511:265-284

* Burgess MG, Costello C, Fredston-Hermann A, Pinsky ML, Gaines SD, Tilman D, Polasky S (2017) Range contraction enables harvesting to extinction. Proc Natl Acad Sci USA 114:3945-3950

Carscadden JE, Nakashima BS (1997) Abundance and changes in distribution, biology and behavior of capelin 
in response to cooler water of the 1990s. In: Forage fishes in marine ecosystems. Proceedings of the International Symposium on the Role of Forage Fishes in Marine Ecosystems. Alaska Sea Grant College Program AK-SG-9701. University of Alaska, Fairbanks, AK, p 457-468

Carscadden J, Nakashima BS, Miller DS (1994) An evaluation of trends in abundance of capelin (Mallotus villosus) from acoustics, aerial surveys and catch rates in NAFO Division 3L, 1982-89. J Northwest Atl Fish Sci 17:45-57

Carscadden JE, Frank KT, Leggett WC (2001) Ecosystem changes and the effects on capelin (Mallotus villosus), a major forage species. Can J Fish Aquat Sci 58:73-85

* Carscadden JE, Gjøsæter H, Vilhjálmsson H (2013) A comparison of recent changes in distribution of capelin (Mallotus villosus) in the Barents Sea, around Iceland and in the Northwest Atlantic. Prog Oceanogr 114:64-83

Chardine JW, Robertson GJ, Ryan PC, Turner B (2003) Abundance and distribution of common murres breeding at Funk Island, Newfoundland in 1972 and 2000. Can Wildl Serv Tech Rep Ser 404

Chavez FP, Ryan J, Lluch-Cota SE, Niquen MC (2003) From anchovies to sardines and back: multidecadal change in the Pacific Ocean. Science 299:217-221

Colbourne E, Holden J, Senciall D, Bailey W, Snook S, Higdon J (2016) Physical oceanographic conditions on the Newfoundland and Labrador Shelf during 2015. DFO Can Sci Advis Sec Res Doc 2016/079

Dalley EL, Anderson JT, deYoung B (2002) Atmospheric forcing, larval drift, and recruitment of capelin (Mallotus villosus). ICES J Mar Sci 59:929-941

Davoren GK (2013) Distribution of marine predator hotspots explained by persistent areas of prey. Mar Biol 160: 3043-3058

Davoren GK, Montevecchi WA (2003) Signals from seabirds indicate changing biology of capelin stocks. Mar Ecol Prog Ser 258:253-261

* Davoren GK, Penton P, Burke C, Montevecchi WA (2012) Water temperature and timing of capelin spawning determine seabird diets. ICES J Mar Sci 69:1234-1241

* Dawe E, Koen-Alonso M, Chabot D, Stansbury D, Mullowney D (2012) Trophic interactions between key predatory fishes and crustaceans: comparison of two Northwest Atlantic systems during a period of ecosystem change. Mar Ecol Prog Ser 469:233-248

deYoung B, Rose GA (1993) On recruitment and distribution of Atlantic cod (Gadus morhua) off Newfoundland. Can J Fish Aquat Sci 50:2729-2741

DFO (Fisheries and Oceans Canada) (1994) Report on the status of pelagic fishes (capelin off Newfoundland and in the Gulf of St. Lawrence, and herring off the east, southeast and south coasts of Newfoundland). DFO Atl Fish Stock Status Rep 1994/3

DFO (2008) Assessment of capelin in SA2+Div. 3KL in 2008. DFO Can Sci Advis Sec Sci Advis Rep 2008/054

₹ DFO (2010) Assessment of capelin in SA2+Div. 3KL in 2010. DFO Can Sci Advis Sec Sci Advis Rep 2010/090

次DO (2013) Assessment of capelin in SA2 + Div. 3KL in 2013. DFO Can Sci Advis Sec Sci Advis Rep 2013/11

DFO (2015) Assessment of capelin in Subarea 2 and Divisions 3KL in 2015. DFO Can Sci Advis Sec Sci Advis Rep 2015/036

DFO (2018) Assessment of capelin in SA2 and Divs. 3KL in 2017. DFO Can Sci Advis Sec Sci Advis Rep 2018/030

* Drinkwater KF (1996) Atmospheric and oceanic variability in the Northwest Atlantic during the 1980s and early 1990s. J Northwest Atl Fish Sci 18:77-97

Frank KT, Leggett WC (1982) Coastal water mass replacement: its effect on zooplankton dynamics and the predator-prey complex associated with larval capelin (Mallotus villosus). Can J Fish Aquat Sci 39:991-1003

Frank KT, Carscadden JE, Simon JE (1996) Recent excursions of capelin (Mallotus villosus) to the Scotian Shelf and Flemish Cap during anomalous hydrographic conditions. Can J Fish Aquat Sci 53:1473-1486

* Frank KT, Petrie B, Boyce D, Leggett WC (2016) Anomalous ecosystem dynamics following the apparent collapse of a keystone forage species. Mar Ecol Prog Ser 553:185-202

Gjøsæter H (1998) The population biology and exploitation of capelin (Mallotus villosus) in the Barents Sea. Sarsia 83:453-496

* Gjøsæter H, Dalpadado P, Hassel A (2002) Growth of Barents Sea capelin (Mallotus villosus) in relation to zooplankton abundance. ICES J Mar Sci 59:959-967

Gjøsæeter H, Bogstad B, Tjelmeland S (2009) Ecosystem effects of the three capelin stock collapses in the Barents Sea. Mar Biol Res 5:40-53

* Gulka J, Carvalho PC, Jenkins E, Johnson K, Maynard L, Davoren GK (2017) Dietary niche shifts of multiple marine predators under varying prey availability on the northeast Newfoundland coast. Front Mar Sci 4:324

Hamre J (1994) Biodiversity and exploitation of the main fish stocks in the Norwegian-Barents Sea ecosystem. Biodivers Conserv 3:473-492

Haug T, Nilssen K (1995) Ecological implications of harp seals Phoca groenlandica invasions in northern Norway. In: Blix AS, Walløe L, Ulltang $\varnothing$ (eds) Whales, seals, fish and man. Developments in Marine Biology, Vol. 4. Elsevier Science, Amsterdam, p 545-556

*Head EJH, Pepin P (2010) Spatial and inter-decadal variability in plankton abundance and composition in the Northwest Atlantic (1958-2006). J Plankton Res 32:1633-1648

* Hjermann DØ, Bogstad B, Dingsør GE, Gjøsæter H, Ottersen G, Eikeset AM, Stenseth NC (2010) Trophic interactions affecting a key ecosystem component: a multistage analysis of the recruitment of the Barents Sea capelin (Mallotus villosus). Can J Fish Aquat Sci 67:1363-1375

*Hop H, Gjøsæeter H (2013) Polar cod (Boreogadus saida) and capelin (Mallotus villosus) as key species in marine food webs of the Arctic and the Barents Sea. Mar Biol Res 9: 878-894

ICES (2017) Report of the North Western Working Group (NWWG). ICES, Copenhagen

Jech JM, McQuinn IH (2016) Towards a balanced presentation and objective interpretation of acoustic and trawl survey data, with specific reference to the eastern Scotian Shelf. Can J Fish Aquat Sci 73:1914-1921

Koen-Alonso M, Fogarty M, Pepin P, Hyde K, Gamble R (2013) Ecosystem production potential in the Northwest Atlantic. NAFO SCR Doc 13/075

* Leggett WC, Frank KT, Carscadden JE (1984) Meteorological and hydrographic regulation of year-class strength in capelin (Mallotus villosus). Can J Fish Aquat Sci 41: 1193-1201

Lilly GR (2005) Southern Labrador and eastern Newfoundland (NAFO Divisions 2J+3KL). ICES Coop Res Rep 274: 138-149

Lilly GR, Davis DJ (1993) Changes in the distribution of capelin in Divisions 2J, 3K and 3L in the autumns of recent years, as inferred from bottom-trawl by-catches and cod stomach examinations. NAFO SCR Doc 93/54 
Lilly GR, Parsons DG, Kulka DW (2000) Was the increase in shrimp biomass on the northeast Newfoundland shelf a consequence of a release in predation pressure from cod? J Northwest Atl Fish Sci 27:45-61

McQuinn IH (2009) Pelagic fish outburst or suprabenthic habitat occupation: legacy of the Atlantic cod (Gadus morhua) collapse in eastern Canada. Can J Fish Aquat Sci 66:2256-2262

Miller DS (1994) Results from an acoustic survey for capelin (Mallotus villosus) in NAFO Divisions 2J3KL in the autumn of 1993. In: Capelin in SA2 + Div. 3KL. DFO Atl Fish Res Doc 94/18, p 91-98

Miller DS (1995) Results from an acoustic survey for capelin (Mallotus villosus) in NAFO Divisions 2J3KL in the autumn of 1994. In: Capelin in SA2 + Div. 3KL. DFO Atl Fish Res Doc 95/70, p 63-71

Miller DS (1997) Results from an acoustic survey for capelin (Mallotus villosus) in NAFO Divisions 3KL in the spring of 1996. In: Capelin in SA2 + Div. 3KL. DFO Can Stock Assess Sec Res Doc 97/29, p 84-90

Miller DS, Carscadden J (1983) Capelin acoustic biomass survey for NAFO Division 2J3K, October 1983. CAFSAC Res Doc 84/79

Miller DS, Lilly GR (1991) Observations and studies on SA2 + Div. 3K capelin in 1991. CAFSAC Res Doc 91/11

Montevecchi WA (2007) Binary dietary responses of northern gannets Sula bassana indicate changing food web and oceanographic conditions. Mar Ecol Prog Ser 352: 213-220

* Montevecchi WA, Myers RA (1997) Centurial and decadal oceanographic influences on changes in northern gannet populations and diets in the Northwest Atlantic: implications for climate change. ICES J Mar Sci 54:608-614

* Morgan MJ, Koen-Alonso M, Rideout RM, Buren AD, Maddock Parsons D (2018) Growth and condition in relation to the lack of recovery of northern cod. ICES J Mar Sci 75:631-641

Mowbray F (2002) Changes in the vertical distribution of capelin (Mallotus villosus) off Newfoundland. ICES J Mar Sci 59:942-949

Mowbray F (2014) Recent spring offshore acoustic survey results for capelin, Mallotus villosus, in NAFO Division 3L. DFO Can Sci Advis Sec Res Doc 2013/040

Mullowney DRJ, Rose GA (2014) Is recovery of northern cod limited by poor feeding? The capelin hypothesis revisited. ICES J Mar Sci 71:784-793

Mullowney D, Maillet G, Dawe E, Rose G, Rowe S (2016) Spawning delays of northern capelin (Mallotus villosus) and recovery dynamics: A mismatch with ice-mediated spring bloom? Prog Oceanogr 141:144-152

Munafò MR, Davey Smith G (2018) Robust research needs many lines of evidence. Nature 553:399-401

Murphy HM, Pepin P, Robert D (2018) Re-visiting the drivers of capelin recruitment in Newfoundland since 1991. Fish Res 200:1-10

NAFO (2014) Report of the 7th Meeting of the NAFO Scientific Council (SC) Working Group on Ecosystem Science Assessment (WGESA). NAFO SCS Doc 14/023

Nakashima B (1996) The relationship between oceanographic conditions in the 1990s and changes in spawning behaviour, growth and early life history of capelin (Mallotus villosus). NAFO Sci Coun Studies 24:55-68

Nakashima BS (1997) Results of the 1996 aerial survey of capelin (Mallotus villosus) schools. In: Capelin in SA2 + Div 3KL. DFO Atl Fish Res Doc 97/29, p 63-73
Nakashima BS, Mowbray F (2014) Capelin (Mallotus villosus) recruitment indices in NAFO Division 3KL. DFO Can Sci Advis Sec Res Doc 2013/091

*Nakashima BS, Wheeler JP (2002) Capelin (Mallotus villosus) spawning behaviour in Newfoundland waters - the interaction between beach and demersal spawning. ICES J Mar Sci 59:909-916

Nilssen KT, Haug T, Øritsland T, Lindblom L, Kjellqwist SA (1998) Invasions of harp seals Phoca groenlandica Erxleben to coastal waters of Norway in 1995: ecological and demographic implications. Sarsia 83:337-345

\%'Driscoll RL, Rose GA (2001) In situ acoustic target strength of juvenile capelin. ICES J Mar Sci 58:342-345

* Obradovich SG, Carruthers EH, Rose GA (2014) Bottom-up limits to Newfoundland capelin (Mallotus villosus) rebuilding: the euphausiid hypothesis. ICES J Mar Sci 71:775-783

*Pálsson ÓK, Gislason A, Guðfinnsson HG, Gunnarsson B and others (2012) Ecosystem structure in the Iceland Sea and recent changes to the capelin (Mallotus villosus) population. ICES J Mar Sci 69:1242-1254

* Pedersen EJ, Thompson PL, Ball RA, Fortin MJ and others (2017) Signatures of the collapse and incipient recovery of an overexploited marine ecosystem. R Soc Open Sci 4: 170215

Pepin P, Colbourne E, Maillet G (2011) Seasonal patterns in zooplankton community structure on the Newfoundland and Labrador shelf. Prog Oceanogr 91:273-285

Pepin P, Higdon J, Koen-Alonso M, Fogarty M, Ollerhead N (2014) Application of ecoregion analysis to the identification of Ecosystem Production Units (EPUs) in the NAFO Convention Area. NAFO SCR Doc 14/069

Core Team (2018) R: a language and environment for statistical computing. R Foundation for Statistical Computing, Vienna

Regular P, Montevecchi W, Hedd A, Robertson G, Wilhelm S (2013) Canadian fishery closures provide a large-scale test of the impact of gillnet bycatch on seabird populations. Biol Lett 9:20130088

* Reid PC, Colebrook JM, Matthews JBL, Aiken J (2003) The Continuous Plankton Recorder: concepts and history, from plankton indicator to undulating recorders. Prog Oceanogr 58:117-173

Renard D, Bez N, Desassis N, Beucher H, Ors F, Freulon X (2018) RGeostats: geostatistical package. http://rgeostats. free.fr

Rose GA (1993) Cod spawning on a migration highway in the north-west Atlantic. Nature 366:458-461

Rose GA, Kulka DW (1999) Hyperaggregation of fish and fisheries: how catch-per-unit-effort increased as the northern cod (Gadus morhua) declined. Can J Fish Aquat Sci 56:118-127

* Rose GA, O'Driscoll RL (2002) Capelin are good for cod: Can the northern stock rebuild without them? ICES J Mar Sci 59:1018-1026

Kose GA, Rowe S (2018) Does redistribution or local growth underpin rebuilding of Canada's northern cod? Can J Fish Aquat Sci 75:825-835

Rose GA, deYoung B, Kulka DW, Goddard SV, Fletcher GL (2000) Distribution shifts and overfishing the northern cod (Gadus morhua): a view from the ocean. Can J Fish Aquat Sci 57:644-663

Schwartzlose RA, Alheit J, Bakun A, Baumgartner TR and others (1999) Worldwide large-scale fluctuations of sardine and anchovy populations. S Afr J Mar Sci 21:289-347 
Skagseth Ø, Slotte A, Stenevik EK, Nash RDM (2015) characteristics of the Norwegian coastal current during years with high recruitment of Norwegian spring spawning herring (Clupea harengus L.). PLOS ONE 10:e0144117

Stenson GB (2012) Estimating consumption of prey by harp seals (Pagophilus groenlandicus) in NAFO Divisions 2J3KL. DFO Can Sci Advis Sec Res Doc 2012/156

Stenson GB, Buren AD, Koen-Alonso M (2016) The impact of changing climate and abundance on reproduction in an ice-dependent species, the Northwest Atlantic harp seal, Pagophilus groenlandicus. ICES J Mar Sci 73: 250-262

Templeman W (1948) The life history of the caplin (Mallotus villosus O. F. Müller) in Newfoundland waters. Bull Nfld Gov Lab 17:1-151

Toresen R, Østvedt OJ (2000) Variation in abundance of Norwegian spring-spawning herring (Clupea harengus, Clupeidae) throughout the $20^{\text {th }}$ century and the influence of climatic fluctuations. Fish Fish 1:231-256

Vilhjálmsson H (1994) The Icelandic capelin stock. Rit Fiskid 13:1-281

Editorial responsibility: Franz Mueter,

Juneau, Alaska, USA
Wilhelm SI, Robertson GJ, Ryan PC, Tobin SF, Elliot RD (2009) Re-evaluating the use of beached bird oiling rates to assess long-term trends in chronic oil pollution. Mar Pollut Bull 58:249-255

Winters GH (1970) Biological changes in coastal capelin from the over-wintering to the spawning condition. J Fish Res Board Can 27:2215-2224

*Winters GH (1995) Interaction between timing, capelin distribution and biomass estimates from the Div. 2J3K capelin acoustic survey. Capelin in SA2 + Div. 3KL. DFO Atl Fish Res Doc 95/70, p 167-179

* Winters GH, Wheeler JP (1985) Interaction between stock area, stock abundance, and catchability coefficient. Can J Fish Aquat Sci 42:989-998

* Woillez M, Poulard JC, Rivoirard J, Petitgas P, Bez N (2007) Indices for capturing spatial patterns and their evolution in time, with application to European hake (Merluccius merluccius) in the Bay of Biscay. ICES J Mar Sci 64:537-550

WWillez M, Rivoirard J, Petitgas P (2009) Notes on surveybased spatial indicators for monitoring fish populations. Aquat Living Resour 22:155-164

Submitted: October 2, 2018; Accepted: March 6, 2019 Proofs received from author(s): April 24, 2019 